\title{
The Conformation of Alkyl Sulfoxides
}

\author{
Julia C. Tai \\ Department of Natural Sciences, University of Michigan-Dearborn, Dearborn, Michigan 48128 \\ Received August 1E, 1980; accepted October 14, 1980
}

\begin{abstract}
Parameters for sulfoxides used in force field MM1 were modified to be incorporated into force field MM2. The conformations of ten alkyl sulfoxides were then calculated using MM2 with these new parameters. The alkyl groups used were methyl, ethyl, isopropyl, and $t$-butyl. It was found that of the many possible conformations for these compounds, only one or two stable conformers exist, and that the number of these conformers agrees with the number of reported $\mathrm{S}-\mathrm{O}$ stretching frequencies in almost every case. No apparent correlation between the vibration frequency and the molecular structure was found.
\end{abstract}

Although the conformation of thiane oxides has been the subject of much experimental study, the conformation of dialkyl sulfoxides has received little attention. $\bar{O} k i$, Oka, and Sakaguchi ${ }^{1}$ measured the $\mathrm{S}-\mathrm{O}$ stretching absorption frequencies of several simple sulfoxides and found that some showed one absorption maximum, whereas others showed two. They attributed this phenomenon to the rotational isomerism about the $\mathrm{S}-\mathrm{C}$ axis and attempted to relate the absorption frequency to the conformation. They also pointed out that Cairns, Eglinton, and Gibson ${ }^{2}$ had made similar measurements and concluded that the multiplicity of the $\mathrm{S}-\mathrm{O}$ stretching frequency could not be explained in terms of the presence of conformers but was believed to be due to Fermi resonance: an overtone of some other vibration which occurs near one-half of the $\mathrm{S}-\mathrm{O}$ vibration frequency. A careful comparison of the papers published by the two groups showed that there was actually no inconsistency of interpretation of the spectra by the two groups. The second absorption peak reported by Cairns' group was at ca. $1020 \mathrm{~cm}^{-1}$, some $20-40$

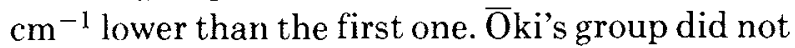
report an absorption in this range. The doublets observed by them were $7-10 \mathrm{~cm}^{-1}$ apart and were observed in compounds, most of which were not studied by the other group. It became clear to us then that the doublets discussed by the groups referred to different pairs of absorption and that the doublets observed by Ōki's group could very likely be due to the existence of rotational isomers as they concluded. Since a force field (MM1) for sulfoxides had been developed by Allinger and $\mathrm{Kao}^{3}{ }^{3}$ we thought we could shed some light on this problem by a systematic calculation of all stable conformations of the dialkyl sulfoxides.

Just when calculations for this study using force field MM1 were completed, a new, improved force field, MM2, became available. ${ }^{4}$ Different parameters for the carbon and hydrogen atoms are used and certain calculational procedures are slightly modified in this new field. The MM2 force field gives improved results on a few selected compounds which could not be treated satisfactorily with force field MM1 due to their unique geometry. For most molecules studied, the two force fields give essentially the same results. In order to do calculations on sulfoxides using this new force field, the parameters for the sulfur and the oxygen atoms would have to be redetermined. We decided to take on this redetermination so that future calculations on sulfoxides may be done using force field MM2. Five pieces of experimental information were used to help determine the parameters: the geometries (bond length and angles) of dimethyl sulfoxide ${ }^{5}$ and of trans-1,4-dithiane-1,4dioxide $^{6}$; the energy difference between 1 -axial- 
Table I. Force field parameters for alkyl sulfoxides.

\begin{tabular}{|c|c|c|}
\hline \multicolumn{3}{|c|}{ van der Waals parameters } \\
\hline Atom & $r^{*}(\AA)$ & $\begin{array}{c}\epsilon \\
(\mathrm{kcal} / \mathrm{mole})\end{array}$ \\
\hline $\mathrm{S}$ & 2.11 & 0.202 \\
\hline $\mathrm{O}$ & 1.74 & 0.066 \\
\hline
\end{tabular}

Bond stretching

\begin{tabular}{ccc} 
Bond & $l_{0}(\AA)$ & $\begin{array}{c}k \\
(\mathrm{mdyn} / \AA)\end{array}$ \\
\hline C-S & 1.805 & 3.64 \\
S-O & 1.480 & 5.00
\end{tabular}

Angle bending

\begin{tabular}{ccc} 
Angle & $\theta_{0}(\mathrm{deg})$ & $\begin{array}{c}k \\
\left(\operatorname{mdyn}^{\AA} / \mathrm{rad}^{2}\right)\end{array}$ \\
\hline C-S-C & 93.3 & 0.72 \\
$\mathrm{C}-\mathrm{C}-\mathrm{S}$ & 108.8 & 0.88 \\
$\mathrm{H}-\mathrm{C}-\mathrm{S}$ & 108.6 & 0.51 \\
$\mathrm{C}-\mathrm{S}-\mathrm{O}$ & 106.0 & 0.72
\end{tabular}

Torsional parameters

\begin{tabular}{|c|c|c|c|}
\hline $\begin{array}{l}\text { Dihedral } \\
\text { angle }\end{array}$ & \multicolumn{3}{|c|}{ Torsional constants ( $\mathrm{kcal} / \mathrm{mole})$} \\
\hline & $V_{1}$ & $V_{2}$ & $V_{3}$ \\
\hline $\mathrm{H}-\mathrm{C}-\mathrm{C}-\mathrm{S}$ & 0 & 0 & 0.510 \\
\hline $\mathrm{C}-\mathrm{C}-\mathrm{S}-\mathrm{O}$ & 0 & -0.230 & 0.510 \\
\hline $\mathrm{C}-\mathrm{C}-\mathrm{S}-\mathrm{C}$ & 0 & 0 & 0.510 \\
\hline $\mathrm{H}-\mathrm{C}-\mathrm{S}-\mathrm{C}$ & 0 & 0 & 0.510 \\
\hline $\mathrm{H}-\mathrm{C}-\mathrm{S}-\mathrm{O}$ & 0 & 0 & 0.285 \\
\hline $\mathrm{C}-\mathrm{C}-\mathrm{C}-\mathrm{S}$ & 0 & 0 & 0.510 \\
\hline \multicolumn{4}{|l|}{ Dipoles } \\
\hline \multirow{2}{*}{\multicolumn{2}{|c|}{ Atom type }} & \multirow{2}{*}{\multicolumn{2}{|c|}{$\begin{array}{l}\text { Bond moment } \\
\text { (D) }\end{array}$}} \\
\hline & & & \\
\hline \multicolumn{2}{|c|}{$\mathrm{C}-\mathrm{S}$} & \multicolumn{2}{|l|}{120} \\
\hline \multicolumn{2}{|c|}{$S-O$} & 3.03 & \\
\hline
\end{tabular}

thiane-oxide and 1-equatorial-thiane oxide ${ }^{7}$; the barrier of rotation ${ }^{5 a}$ about the $\mathrm{C}-\mathrm{S}$ bond and the dipole moment ${ }^{8}$ of dimethyl sulfoxide. We took the parameters used by Allinger and Kao as a starting point and studied how each affected the calculation. Where improvements were needed, the responsible parameters were varied one or more at a time by successive approximation until the results were satisfactory. The parameters determined are given in Table I and the calculated data for the above-mentioned information are compared with those calculated using MM1 and with observed data in Table II. To provide more information for comparison, the conformational energies of two thiane oxides were calculated. It has been observed ${ }^{9}$ that the 1 -axial preference persists in 4,4-dimethyl thiane 1-oxide with $\Delta G=0.31$ kcal, while the equatorial conformation predominates in 3,3-dimethyl thiane 1 -oxide at $90^{\circ} \mathrm{C}$. Our calculation predicted $\Delta G=0.21 \mathrm{kcal}$ for the former favoring the axial form and $\Delta G=0.94 \mathrm{kcal}$ for the latter favoring the equatorial form.

It should be pointed out that in force field calculations there are often not enough experimental data available to determine uniquely every parameter and that several possible parameter combinations may fit a set of reference data equally well. In the present case, most of the torsional parameters presented here may assume a different value and still predict the same groundstate energy and geometry for the molecules discussed. When more information is available, these parameters could be redetermined. The torsional parameters that do have an important effect on the present calculations are the twofold barrier that is found necessary for dihedral angle $\mathrm{C}-\mathrm{C}-\mathrm{S}-\mathrm{O}$ in order to predict correctly the energy difference between the axial and equatorial isomers of 1 thiane oxide, and the threefold barriers of angles $\mathrm{H}-\mathrm{C}-\mathrm{S}-\mathrm{C}$ and $\mathrm{H}-\mathrm{C}-\mathrm{S}-\mathrm{O}$ that are determined to fit the rotational barrier of the methyl group in DMSO.

The molecule dimethyl sulfoxide (DMSO) was found to have a $C_{s}$ symmetry with the two methyl groups staggered with respect to the $\mathrm{S}-\mathrm{O}$ bond. ${ }^{5 \mathrm{a}}$ The three hydrogen atoms of the methyl group are not equivalent. We shall refer to them as $\mathrm{H}_{x}, \mathrm{H}_{y}$, and $\mathrm{H}_{z}$. The following diagram illustrates the structure:

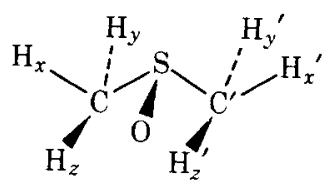

The atoms $\mathrm{H}_{x}, \mathrm{C}, \mathrm{S}, \mathrm{C}^{\prime}$, and $\mathrm{H}_{x}{ }^{\prime}$ are nearly in a plane. Atoms $\mathrm{H}_{y}$ and $\mathrm{H}_{y^{\prime}}$ are at one side of this plane and atoms $\mathrm{H}_{z}, \mathrm{H}_{z}{ }^{\prime}$, and $\mathrm{O}$ are at the other side. We shall investigate all dialkyl sulfoxides resulting from substituting methyl groups for one or more of the hydrogen atoms in DMSO. We shall use the letters $X, Y$, and $Z$ to denote the position of methyl substitution. For instance, if $\mathrm{H}_{x}{ }^{\prime}$ is substituted, the resulting compound is called methyl ethyl sulfoxide $-X$; if $\mathrm{H}_{x}, \mathrm{H}_{x}{ }^{\prime}$, and $\mathrm{H}_{y}{ }^{\prime}$ are substituted, we have ethyl isopropyl sulfoxide $X-X Y$, etc. The sign and magnitude of the di- 
Table II. Comparison of calculated and experimental data of some sulfoxides.

Dimethyl sulfoxide

\begin{tabular}{|c|c|c|c|c|}
\hline \multirow[b]{2}{*}{ Geometry } & \multicolumn{2}{|c|}{ Calculated } & \multicolumn{2}{|c|}{ Observed } \\
\hline & $\begin{array}{c}\text { Allinger } \\
\text { and Kao }\end{array}$ & $\begin{array}{l}\text { This } \\
\text { work } \\
\end{array}$ & Microwave $^{5 a}$ & X ray ${ }^{5 t}$ \\
\hline $\mathrm{C}-\mathrm{S}$ & $1.809 \AA$ & 1.805 & $1.799 \pm 0.005$ & $1.801 \pm 0.010$ \\
\hline $\mathrm{S}-\mathrm{O}$ & $1.480 \AA$ & 1.480 & $1.485 \pm 0.006$ & $1.471 \pm 0.008$ \\
\hline$\Varangle \mathrm{C}-\mathrm{S}-\mathrm{O}$ & $108.1^{\circ}$ & 106.9 & 106.7 & $107.2 \pm 0.6$ \\
\hline$\Varangle \mathrm{C}-\mathrm{S}-\mathrm{C}$ & $96.9^{\circ}$ & 96.6 & 96.6 & \pm 0.5 \\
\hline$\Varangle \mathrm{O}-\mathrm{S}-\mathrm{C}--\mathrm{H}_{x}$ & & -67 & -71.4 & \\
\hline$\nless \mathrm{O}-\mathrm{S}-\mathrm{C}-\mathrm{H}_{y}$ & & 52 & 52.1 & \\
\hline$\Varangle \mathrm{O}-\mathrm{S}-\mathrm{C}-\mathrm{H}_{z}$ & & 173 & 172.7 & \\
\hline Dipole moment & $4.03 \mathrm{D}$ & 4.00 & $3.9 \pm 0.1^{8}$ & \\
\hline Rotational barrier & $3.06 \mathrm{kcal}$ & 2.97 & $2.983^{5 \mathrm{a}}$ & \\
\hline
\end{tabular}

trans-1,4-Dithiane-1,4-dioxide

\begin{tabular}{cccc} 
Geometry & \multicolumn{1}{c}{$\mathrm{X} \mathrm{ray}^{6}$} \\
\hline C-S & $1.809 \AA$ & 1.805 & $1.81 \pm 0.02$ \\
S-O & $1.479 \AA$ & 1.478 & $1.48 \pm 0.01$ \\
C-C & $1.537 \AA$ & 1.538 & $1.51 \pm 0.03$ \\
$\Varangle \mathrm{C}-\mathrm{S}-\mathrm{C}$ & $97.9^{\circ}$ & 98.5 & $97.9 \pm 0.8$ \\
$\Varangle \mathrm{C}-\mathrm{C}-\mathrm{S}$ & $112.3^{\circ}$ & 112.7 & $112.3 \pm 1.3$ \\
$\Varangle \mathrm{C}-\mathrm{S}-\mathrm{O}$ & $107.5^{\circ}$ & 107.2 & $107.4 \pm 0.8$ \\
Thiane-1-oxide & & & \\
Energy & & & \\
equatorial & $0.15 \mathrm{kcal}$ & 0.18 & $0.18^{7}$ \\
axial & 0.00 & 0.00 & 0.00 \\
\hline
\end{tabular}

hedral angle $I J K L$ are determined by the following convention: The angle is equal to zero when $I$ and $L$ are eclipsed. Looking down the axis $J-K(J$ closer to the observer), if $L$ is counterclockwise from $I$, the sign of the angle is negative; if $L$ is clockwise from $I$, it is positive. It should be noted that, in all instances, steric hindrance forces rotations about the $\mathrm{C}-\mathrm{S}$ bond so that the positions $X, Y$, and $Z$ differ somewhat from those in DMSO, namely dihedral angle $\operatorname{OSC} X=67^{\circ}$, $\operatorname{OSC} Y=-173^{\circ}$, and $\operatorname{OSC} Z=-52^{\circ}$. Nevertheless, the use of the notation $X, Y$, and $Z$ remains.

In Table III are collected the calculated relative steric energies of all stable conformations of all compounds studied. The population fraction of each conformer in an equilibrium mixture at $25^{\circ} \mathrm{C}$ was calculated and presented in Table III.

For dimethyl sulfoxide, only one stable isomer was predicted by the calculation. The $X$ hydrogens of the methyl groups, which, for the perfectly staggered conformation, would have been located on the CSC' plane, are calculated to be staggered $7^{\circ}$ out of this plane away from the oxygen atom. Rotational barrier of a methyl group about the $\mathrm{SO}$ bond was found to be $2.97 \mathrm{kcal} / \mathrm{mole}$ compared to an experimental value of $2.983 \mathrm{kcal} / \mathrm{mole}^{5 \mathrm{a}} \mathrm{Ro}$ binet et al. ${ }^{10}$ using the $\mathrm{CNDO} / 2$ approximation found that the $X$ hydrogens are about $4^{\circ}$ away from the perfectly staggered conformation toward the oxygen atom. They calculated a rotational barrier of $3.5 \mathrm{kcal} / \mathrm{mole}$.

In a recent $a b$ initio study ${ }^{11}$ employing a minimum $3 \mathrm{G}$ basis set, the methyl groups were found to be perfectly staggered with respect to the SO bond with a rotational barrier of $1.5 \mathrm{kcal}$.

Three rotational isomers were predicted for methyl ethyl sulfoxide. The relative steric energies of the $-X,-Y$, and $-Z$ forms are $0.00,0.76$, and $1.11 \mathrm{kcal} / \mathrm{mole}$, respectively. The higher-energy forms show higher bending energy and lower van der Waal's energy which is a measure of the repulsion between nonbonded atoms. The deformation of the angle $\mathrm{CSC}^{\prime}$ and of the various angles $\mathrm{HCH}$ from their equilibrium values are chief contributors to the bending energies. The barrier of rotation for the ethyl group about the $\mathrm{S}-\mathrm{C}^{\prime}$ bond is calculated to be about $3.0 \mathrm{kcal} / \mathrm{mole}$ when the rotation brings the methyl group from the $X$ 
Table III. Absorption frequencies due to $\mathrm{S}-\mathrm{O}$ stretching and relative steric energies of different conformations of alkyl sulfoxides.

\begin{tabular}{|c|c|c|c|c|}
\hline & $\begin{array}{c}\nu_{\max }(\epsilon)^{\mathrm{a}} \\
\left(\mathrm{cm}^{-1}\right)\end{array}$ & $\begin{array}{c}\text { Conforma- } \\
\text { tion }^{b}\end{array}$ & $\begin{array}{c}\text { Steric energy } \\
(\mathrm{kcal} / \mathrm{mole})\end{array}$ & $\begin{array}{l}\text { Equilibrium } \\
\text { fraction }\end{array}$ \\
\hline Dimethyl sulfoxide & $1069(385)$ & $-c$ & 0.00 & 1.00 \\
\hline \multirow[t]{3}{*}{ Methyl ethyl sulfoxide } & \multirow{3}{*}{$1065(186)$} & $-X$ & 0.00 & 0.70 \\
\hline & & $-Y$ & 0.76 & 0.20 \\
\hline & & $-Z$ & 1.11 & 0.10 \\
\hline \multirow[t]{3}{*}{ Methyl isopropyl sulfoxide } & \multirow[t]{3}{*}{$1065(268), 1054(245)$} & $-X Y$ & 0.00 & 0.53 \\
\hline & & $-X Z$ & 0.23 & 0.36 \\
\hline & & $-Y Z$ & 0.92 & 0.11 \\
\hline Methyl $t$-butyl sulfoxide & $1058(356)$ & $-X Y Z$ & 0.00 & 1.00 \\
\hline \multirow[t]{6}{*}{ Diethyl sulfoxide } & \multirow[t]{6}{*}{$1065(250), 1058(\underline{210})$} & $X-X^{\mathrm{c}}$ & 0.00 & 0.52 \\
\hline & & $Y \ldots-X$ & 0.81 & 0.27 \\
\hline & & $Z-X$ & 1.13 & 0.16 \\
\hline & & $Z-Y$ & 1.88 & 0.04 \\
\hline & & $Y-Y$ & 2.95 & 0.01 \\
\hline & & $Z-Z$ & 3.79 & 0.00 \\
\hline \multirow[t]{13}{*}{ Ethyl isopropyl sulfoxide } & \multirow[t]{13}{*}{$1065(178), 1056(245)$} & $X-X Y$ & 0.00 & 0.42 \\
\hline & & $X-X Z$ & 0.17 & 0.32 \\
\hline & & $X-Y Z$ & 0.89 & 0.09 \\
\hline & & $Y-X Z$ & 0.99 & 0.08 \\
\hline & & $Z-X Y$ & 1.03 & 0.07 \\
\hline & & $Y-X Y$ & 2.12 & 0.01 \\
\hline & & $(Y-X Y)^{*}$ & 2.62 & 0.00 \\
\hline & & $Z-X Z$ & 2.85 & 0.00 \\
\hline & & $(Z-X Z)^{*}$ & 2.99 & 0.00 \\
\hline & & $Y-Y Z$ & 3.22 & 0.00 \\
\hline & & $(Y-Y Z)^{*}$ & 3.58 & 0.00 \\
\hline & & $Z-Y Z$ & 3.58 & 0.00 \\
\hline & & $(Z-Y Z)^{*}$ & 4.44 & 0.00 \\
\hline \multirow[t]{5}{*}{ Ethyl $t$-butyl sulfoxide } & \multirow[t]{5}{*}{$1056(315), 1045(244)$} & $X-X Y Z$ & 0.00 & 0.92 \\
\hline & & $Y-X Y Z$ & 2.28 & 0.07 \\
\hline & & $Z-X Y Z$ & 2.74 & 0.01 \\
\hline & & $(Y-X Y Z)^{*}$ & 3.24 & 0.00 \\
\hline & & $(Z-X Y Z)^{*}$ & 3.71 & 0.00 \\
\hline \multirow[t]{8}{*}{ Diisopropyl sulfoxide } & \multirow[t]{8}{*}{$1058(312)$} & $X Z-X Y$ & 0.00 & 0.89 \\
\hline & & $X Y-X Y$ & 1.66 & 0.05 \\
\hline & & $X Z-X Z$ & 1.90 & 0.04 \\
\hline & & $Y Z-X Z$ & 2.55 & 0.01 \\
\hline & & $Y Z-X Y$ & 2.65 & 0.01 \\
\hline & & $(Y Z-X Y)^{*}$ & 2.83 & 0.00 \\
\hline & & $(Y Z-X Z)^{*}$ & 3.54 & 0.00 \\
\hline & & $Y Z-Y Z$ & 6.04 & 0.00 \\
\hline \multirow[t]{5}{*}{ Isopropy. $t$-butyl sulfoxide } & \multirow[t]{5}{*}{$1050(300), 1040(\underline{160})$} & $X Z-X Y Z$ & 0.00 & 0.45 \\
\hline & & $X Y-X Y Z$ & 0.01 & 0.44 \\
\hline & & $(X Y-X Y Z)^{*}$ & 0.86 & 0.11 \\
\hline & & $Y Z-X Y Z$ & 3.81 & 0.00 \\
\hline & & $(Y Z-X Y Z)^{*}$ & 4.12 & 0.00 \\
\hline Di-t-butyl sulfoxide & $1040(412)$ & $X Y Z-X Y Z$ & 0.00 & 1.00 \\
\hline
\end{tabular}

a From ref. 1 . Observed in ca. 0.1 -mole/liter solution in carbon tetrachloride. The frequencies are listed here without reference to any particular conformation. Absorptions with their $\epsilon$ underlined were observed as shoulders.

b See text for explanation of notation.

c Conformer possesses $C_{s}$ symmetry.

position to the $Y$ position, about $3.8 \mathrm{kcal}$ from the $X$ position to the $Z$ position, and about $5.2 \mathrm{kcal}$ from the $Y$ position to the $Z$ position. The data for this compound reveal that a methyl group at the
$X$ position is of the lowest energy; at the $Y$ position, of higher energy; and at the $Z$ position of the highest energy. A survey of the data in Table III shows that the increment in energy from an $X$ - 
Table IV. Dihedral angles (deg) of dimethyl sulfoxide and diethyl sulfoxide. ${ }^{a}$

\begin{tabular}{ccccccc}
\hline & $\Varangle \mathrm{OSC} X$ & $\Varangle \mathrm{OSCY}$ & $\Varangle \mathrm{OSCZ}$ & $\Varangle \mathrm{OSC}^{\prime} X^{\prime}$ & $\Varangle \mathrm{OSC}^{\prime} Y^{\prime}$ & $\nless \mathrm{OSC}^{\prime} Z^{\prime}$ \\
\hline $\begin{array}{l}\text { Dimethyl sulfoxide } \\
\text { Diethyl sulfoxide }\end{array}$ & 67.4 & -173.4 & -52.4 & -67.4 & 173.4 & 52.4 \\
$X-X$ & & & & & & \\
$Y-X$ & 68.5 & -171.1 & -52.7 & -68.6 & 171.0 & 52.7 \\
$Z-X$ & 56.7 & 176.1 & -60.0 & -64.8 & 175.3 & 56.4 \\
$Z-Y$ & 72.4 & -171.8 & -48.2 & -73.3 & 166.3 & 47.2 \\
$Y-Y$ & 65.7 & -179.1 & -54.6 & -64.3 & 176.3 & 51.4 \\
$Z-Z$ & 30.7 & 149.0 & -86.3 & -62.3 & 178.0 & 53.9 \\
\hline$-Z$
\end{tabular}

a For sign of angle and conformer notation, see text for explanation.

methyl to a $Y$-methyl group is $0.6-0.8 \mathrm{kcal} /$ mole, from a $Y$-methyl group to a $Z$-methyl group $0.2-0.5 \mathrm{kcal} / \mathrm{mole}$, except when both $Y$ positions or both $Z$ positions are substituted, then the steric energy increases by a disproportionately large amount. It is also generally true that $Z-Z$ substitution is of higher energy than $Y-Y$ substitution. In dialkyl sulfides, the $Y$ and $Z$ positions are equivalent. Force field calculations ${ }^{12}$ predicted the $X$-methyl substitution to be more favorable than the $Y$ or $Z$ substitution by about $0.3 \mathrm{kcal}$.

It should be pointed out that the presence of the twofold term in the torsional potential of $\Varangle$ CCSO favors the $X$ and the $Z$ positions in alkyl sulfoxides. Yet a combination with other factors put the $Y$-methyl substitution at $0.2-0.5 \mathrm{kcal} / \mathrm{mole}$ lower in energy than the $Z$-methyl substitution.

Three conformers are predicted for methylisopropyl sulfoxide. Increasing bending energy as a result of increasing angle $\mathrm{CSC}^{\prime}$ and crowding within the isopropyl group account for the higher energy in the $-X Z$ and $-Y Z$ forms.

For diethyl sulfoxide, five conformers are expected and predicted. The $X-X$ conformer has a $C_{s}$ symmetry and is of the lowest energy. In the $Y-Y$ and $Z-Z$ conformers, to avoid crowding between the two methyl groups, one of the ethyl groups rotates about the $\mathrm{C}-\mathrm{S}$ bond by more than $30^{\circ}$ from the staggered position as in DMSO while the other remairis essentially at near-staggered position. In diethyl sulfoxide $Z-Z$, the rotation is in the direction that brings the methyl group closer to the $\mathrm{S}-\mathrm{O}$ bond or decreases the absolute value of the $\mathrm{OSCC}_{z}$ angle. In diethyl sulfoxide $Y \ldots Y$, the rotation is in the opposite direction. As this is typical of all other compounds that possess $Y-Y$ or $Z-Y$ substitution, the dihedral angles of diethyl sulfoxide $Y-Y$ and $Z-Z$ are presented in Table IV together with those of dimethyl sulfoxide and of the other conformers of diethyl sulfoxide for comparison. The $Y-Y$ and $Z-Z$ conformers do not possess $C_{s}$ symmetry and are expected to exist as $d-l$ pairs. The rotational barriers between the $d$ and $l$ forms are 0.4 and $0.7 \mathrm{kcal} /$ mole for the $Y-Y$ and $Z-Z$ conformers, respectively.

Instead of 9 conformers that were expected of ethyl isopropyl sulfoxide, 13 were predicted by calculation. There are two conformers to each of the combinations $Y-X Y, Z-X Z, Y-Y Z$, and $Z-Y Z$. Notice that there is either $Y-Y$ or $Z-Z$ substitution in these conformations. The higherenergy one of each pair is to be designated with a superscript asterisk, e.g., $(Y-X Y)^{*}$. The rotational barriers between these pairs are small, from 0.5 to $0.9 \mathrm{kcal} / \mathrm{mole}$. The conformation with lower energy has the isopropyl group staggered and the ethyl group rotated about the S-C bond by about $30^{\circ}$ from the staggered position. On the other hand, the conformation with higher energy has the ethyl group staggered and the isopropyl group rotated. The direction of rotation depends on whether there are two $Y$-methyl groups or two $Z$-methyl groups. It is in the same way as described earlier for diethyl sulfoxide.

For ethyl $t$-butyl sulfoxide, calculations predict two conformers each for the combinations $Y-X Y Z$ and $Z-X Y Z$. Those conformers with lower energy, $Y-X Y Z$ and $Z-X Y Z$, have their ethyl group rotated by nearly $30^{\circ}$ and those with higher energy, $(Y-X Y Z)^{*}$ and $(Z-X Y Z)^{*}$, have the $t$-butyl group rotated by about $15^{\circ}$. The barriers of rotation of these two pairs are only about $0.3 \mathrm{kcal} / \mathrm{mole}$. 
Of the six conformations expected of diisopropyl sulfoxide, two conformers each were found for $Y Z-X Y$ and $Y Z-X Z$. Conversions between the pairs and between most of the conformers have very low energy barriers, $1 \mathrm{kcal} /$ mole or less.

Five conformers were predicted for isopropyl $t$-butyl sulfoxide of which the $X Z-X Y Z$ and $X Y-X Y Z$ were found to have nearly identical energy while all of the others have considerably higher energies.

Next we shall examine the variation of bond lengths, bond angles, and dihedral angles. The $\mathrm{S}-\mathrm{O}$ bond length $R_{\mathrm{SO}}$ is found to vary very little, from 1.476 to $1.482 \AA$. It appears that $R_{\mathrm{SO}}$ tends to be smaller when $Z$-methyl groups are present and larger when $Y$-methyl groups are present. The value of $R_{\mathrm{SC}}$ increases with the number of methyl groups attached to $\mathrm{C}$. It is $1.800-1.805,1.802-$ $1.814,1.809-1.822$, and $1.820-1.829 \AA$ when the number is $0,1,2$, and 3 , respectively. With the same number of attached methyl groups, it is shorter when $\mathrm{C}^{\prime}$ and/or $\mathrm{C}$ carries a $Z$-methyl group. $R_{\mathrm{CC}_{X}}$ varies from 1.534 to $1.551 \AA$ as the number of methyl groups on $\mathrm{C}$ increases. With the same number of methyl groups on $\mathrm{C}$, it appears that $R_{\mathrm{CC}_{X}}$ becomes longer with more methyl groups on $\mathrm{C}^{\prime} . R_{\mathrm{CC}_{Y}}$ and $R_{\mathrm{CC}_{Z}}$ also increase with increasing number of methyl groups on $\mathrm{C}$. However, these bond lengths do not seem to be affected by the number of methyl groups on $\mathrm{C}^{\prime}$, and, in general, they are slightly shorter than the corresponding $R_{\mathrm{CC}_{X}}$.

Bond angles $\mathrm{OSC}$ and $\mathrm{OSC}^{\prime}$ vary very little; they are between $104.9^{\circ}$ and $109.1^{\circ}$. Bond angle $\mathrm{CSC}^{\prime}$ varies from $96.6^{\circ}$ in DMSO to $111.9^{\circ}$ in di- $t$-butyl sulfoxide. For a given compound, conformations with higher energy usually have larger angle CSC $^{\prime}$ unless both $\mathrm{C}$ and $\mathrm{C}^{\prime}$ carry $Y$ - or $Z$-methyl groups. In those cases, larger rotation about the $\mathrm{S}-\mathrm{C}$ or $\mathrm{S}-\mathrm{C}^{\prime}$ bond is able to release some of the crowding thus permitting a smaller $\mathrm{CSC}^{\prime}$ angle.

Dihedral angles span a much wider range than bond angles. While for most conformation rotation about the $\mathrm{S}-\mathrm{C}$ or $\mathrm{S}-\mathrm{C}^{\prime}$ bond from the position in DMSO is less than $10^{\circ}$, in compounds that carry two $Y$-methyl or two $Z$-methyl groups, rotation amounts to more than $30^{\circ}$. This has been demonstrated above for diethyl sulfoxide.
A comparison between our results and the $\overline{\mathrm{O}} \mathrm{ki}$ et al. observation shows that the number of stable conformers (here we refer to conformers present at larger than $20 \%$ in the equilibrium mixture at room temperature) predicted is equal to the number of stretching frequencies observed for every compound but ethyl $t$-butyl sulfoxide. Our calculation predicts conformation $X-X Y Z$ to exist almost exclusively while two $\mathrm{S}-\mathrm{O}$ stretching frequencies were observed which were attributed to the presence of two conformers. We are thus unable to account for the discrepancy between calculated and observed data in this case. When it comes to the relation between a certain frequency range and a certain conformation type, we are not able to match the $\overline{\mathrm{O}} \mathrm{ki}$ et al. assignment. Their assignment was made on the basis of an assumption that the frequency is a function of three conformation types: type I with S-O staggering between two hydrogens, type II with S-O staggering one hydrogen and one methyl, and type III with S--O staggering two methyl groups. In two cases their assignment leads to conclusions which would seem extremely unlikely. For ethyl isopropyl sulfoxide, one of the absorptions observed was assigned to conformers $Y-X Y$ and/or $Y-Y Z$ which are predicted by us to be present in negligible amounts. Based on simple steric consideration, one can conclude that $Y-X Y$ and $Y-Y Z$ are much less stable than $X-X Z$. Yet the latter conformer was present in a negligible amount according to $\overline{\mathrm{O}} \mathrm{ki}$ et al. ${ }^{1}$ Diisopropyl sulfoxide was observed to have a single stretching frequency of $1058 \mathrm{~cm}^{-1}$ which would be due to conformers $X Y-X Y, Y Z-X Y$, or $Y Z-Y Z$, while $X Z-X Y$ is obviously the most stable conformer.

An attempt was made to correlate the absorption frequencies with the molecular structure. Bond lengths, bond angles, as well as positions of methyl group substitutions were looked at. No apparent correlation was found.

In conclusion we observe that although several, sometimes from six to more than ten, conformations are possible for some dialkyl sulfoxides, only one or two are predominant. The rotational barriers about the $\mathrm{S}-\mathrm{C}$ bond range from 2 to 10 $\mathrm{kcal} /$ mole except when the rotation is between a $d-l$ pair or between pairs with similar substitution 
patterns such as $Z-X Z$ and $(Z-X Z)^{*}$. In these cases, rotational barriers are usually less than 1 $\mathrm{kcal} / \mathrm{mole}$. The question of whether one should treat these as separate conformers is immaterial, for they invariably represent very high-energy species and are present in negligible amount in the equilibrium mixture. The absorption frequency due to $\mathrm{S}-\mathrm{O}$ stretching appears to be different for different conformers. However, there is no apparent correlation between a certain conformation type and the frequency. Moreover, one cannot rule out the possibility that more than one conformer may give rise to the same vibration frequency.

\section{References}

1. M. Ōki, I. Oka, and K. Sakaguchi, Bull. Chem. Soc.
Jpn., 42, 2944 (1969).

2. T. Cairns, G. Eglinton, and D. T. Gibson, Spectrochim. Acta, 20, 31 (1964).

3. N. L. Allinger and J. Kao, Tetrahedron, 32, 529 (1976).

4. N. L. Allinger, J. Am. Chem. Soc., 99, 8127 (1977).

5. (a) W. Feder, H. Dreizler, H. D. Rudolf, and V. Typke, Z. Naturforsch., 24a, 266 (1969); (b) M. A. Viswamitra and K. K. Kannan, Nature (London), 209, 1016 (1966).

6. H. M. M. Shearer, J. Chem. Soc., 1394 (1959).

7. J. B. Lambert and R. G. Keske, J. Org. Chem., 31, 3429 (1966).

8. F. A. Cotton and R. Francis, J. Am. Chem. Soc., 82, $2986(1960)$

9. J. B. Lambert, D. S. Bailey, and C. E. Mixan, J. Org. Chem., 37, 377 (1972).

10. G. Robinet, C. Leibovici, and J.-F. Labarre, Theor Chim. Acta Berlin, 26, 257 (1972).

11. P. G. Mezey and A. Kapur, Can. J. Chem., 58, 559 (1980).

12. N. L. Allinger and M. J. Hickey, J. Am. Chem. Soc., 97, 5167 (1975). 